\title{
El enfoque por tareas en la didáctica de la traducción jurídica: propuesta de aplicación
}

\author{
Gemma Andúuar Moreno / M. ${ }^{\mathrm{a}}$ Dolors Cañada Pujols ${ }^{1}$ \\ Universitat Pompeu Fabra \\ gemma.andujar@upf.edu / dolores.canada@upf.edu
}

Recibido: 18 de septiembre de 2010

Aceptado: 30 de noviembre de 2010

\section{RESUMEN}

La implantación generalizada del Espacio Europeo de Educación Superior trae aparejada la necesidad de dejar de centrar los procesos de enseñanza / aprendizaje en la magistralidad del profesor y permitir al aprendiz convertirse en el gestor de su propio aprendizaje. A partir de esta premisa básica, en este trabajo presentamos una propuesta didáctica centrada en la traducción jurídica francés-castellano, donde el trabajo por competencias y el fomento de la autonomía del aprendiz desempeñan un papel preponderante. En ella tratamos de articular las distintas dimensiones de la traducción jurídica mediante una aproximación global y por tareas al acto traductor.

Palabras clave: Espacio Europeo de Educación Superior, didáctica de la traducción, traducción jurídica francés-castellano.

Task-based work in legal translation teaching: a practical proposal

\begin{abstract}
The establishment of the European Higher Education Area brings along the need not to focus the teaching/learning processes merely upon the teacher's lectures but to allow the student to manage his own learning process. Taking this fact as a basic premise, this study puts forward a didactic proposal for French-Spanish legal translation in which task-based work and

\footnotetext{
1 Gemma Andújar Moreno forma parte del grupo de investigación consolidado CEDIT (Centro de Estudios de Discurso y Traducción), con número de expediente 2009 SGR 771, reconocido por la AGAUR de la Generalitat de Catalunya. Maria Dolors Cañada Pujols es miembro del grupo consolidado Gr@el - Grup de recerca sobre aprenentatge i ensenyament de llengües, que es un grupo de investigación consolidado reconocido por la Generalitat de Catalunya (AGAUR, $n^{\circ}$ de expediente 2009 SGR 803).
} 
encouragement of the learner autonomy play an essential role. The proposal tries to fit together the different aspects of legal translation using a global and task-based approach.

Keywords: European Higher Education Area, translation teaching, legal translation (from French into Spanish).

Sumario: 1. Introducción. 2. Fundamentos teóricos de partida. 3. La unidad didáctica: definición y descripción de los elementos constitutivos. 3.1. El texto original y la ficha de comprensión. 3.2. La ficha pedagógica. 3.3. El material complementario. 4. Aplicación práctica: organización de las actividades. 5. Conclusiones.

\section{Introducción}

La didáctica de la traducción jurídica enfrenta al docente con la dificultad de articular en la docencia el conocimiento sobre el campo temático en que se inscribe el texto original con los problemas lingüísticos, textuales y culturales que plantea la traducción especializada. En efecto, como es bien sabido, la traducción jurídica constituye una modalidad muy marcada por el campo del conocimiento en el que se inscribe, el Derecho, y por la necesidad de que los textos se ajusten a los distintos sistemas jurídicos implicados. Por otra parte, la especificidad del lenguaje jurídico puede inducir a otorgar un papel preponderante a los problemas terminológicos en clase de traducción, en detrimento de otros factores textuales y culturales de igual importancia para la configuración del producto final. El docente se enfrenta, por lo tanto, a una modalidad de traducción compleja, con unas características muy específicas que le obligan a establecer un complicado equilibrio entre lo lingüístico y lo cultural.

En este trabajo presentamos una propuesta didáctica que trata de articular las distintas dimensiones de la traducción jurídica mediante una aproximación global y por tareas al acto traductor. La propuesta que presentamos se inscribe en el ámbito de la traducción jurídica del francés al castellano, aunque también es aplicable, con las necesarias modificaciones, a otros tipos de traducción especializada y otras combinatorias lingüísticas. Más concretamente, está concebida para estudiantes que se inician en la traducción especializada, ya sea en las antiguas licenciaturas ya sea en el marco de los nuevos estudios de grado ${ }^{2}$.

\section{Fundamentos teóricos de partida}

La elaboración de una propuesta metodológica para la didáctica de la traducción jurídica exige determinar, como punto de partida, cuál es la concepción de la tra-

\footnotetext{
${ }^{2}$ La propuesta se inscribía inicialmente en la asignatura "Traducción jurídico-económica B-A I (francés-castellano/catalán)" de la Licenciatura en Traducción e Interpretación que se impartía en la Universitat Pompeu Fabra hasta la puesta en marcha del nuevo grado en Traducción e Interpretación.
} 
ducción que va a apuntalarla. De un modo general, la propuesta que presentamos parte de una concepción de la traducción como un acto de comunicación complejo, que supera la mera confrontación lingüística para constituir una auténtica mediación entre formas distintas de ver el mundo, donde se entrecruzan sistemas lingüísticos, culturas y puntos de vista diferentes. En el caso particular de la traducción jurídica, como afirma Gémar (1995), nos encontramos ante un trasvase intercultural con doble campo, el lingüístico y el jurídico, pues la especificidad del lenguaje jurídico y de los elementos que lo constituyen está enraizada en la misma sociedad que los genera.

Desde nuestra perspectiva, el acto de traducción jurídica se aborda desde una óptica funcional (Nord, 1997). El traductor selecciona el material lingüístico y textual que le permite ajustarse a las instrucciones que ha recibido de su cliente tomando en consideración la situación de comunicación y la función del texto traducido en la cultura jurídica meta. Este enfoque permite, por lo tanto, situar el acto traductor imbricado en su contexto comunicativo, determinado por las condiciones de producción y recepción que le son propias. La traducción jurídica se concibe, pues, como una correspondencia entre dos discursos jurídicos y no únicamente entre dos sistemas lingüísticos determinados.

Desde esta óptica funcional es fácil asociar el concepto de encargo de traducción -cada vez más extendido en el ámbito de la enseñanza de la traducción- al concepto de tarea surgido en el ámbito de la enseñanza de lenguas extranjeras y por el que aboga de modo inequívoco el Marco Común Europeo de Referencia (2001) del Consejo de Europa.

En este sentido, la tarea se puede definir como "una iniciativa -pedagógicamente estructurada- para el aprendizaje de la lengua" o, dicho de otro modo, "el conjunto de actividades de aula que conforman esta nueva unidad de trabajo [...], una especie de constelación de prácticas discentes interrelacionadas y agrupadas" (Martín Peris, 2004). En esta misma perspectiva, Hurtado Albir (1999) la define como: "Una unidad de trabajo en el aula, representativa de la práctica traductora, que se dirige intencionalmente al aprendizaje de la traducción y que está diseñada con un objetivo concreto, una estructura y una secuencia de trabajo" (Hurtado Albir, 1999: 56).

Cabe subrayar que los principios didácticos que subyacen a este enfoque privilegian el papel interactivo de los aprendices, que van construyendo su saber a partir de experiencias auténticas, porque "lo esencial radica no solamente en el hecho de enseñar a los alumnos una materia, sino también en integrarlos poco a poco en la comunidad profesional de traductores" (González Davies, 2003: 10).

La propuesta que aquí presentamos se inscribe plenamente en este enfoque al que aporta un elemento adicional. En efecto, nuestras unidades de trabajo traspasan el límite del aula insertándose en una globalidad en la que se alternan las fases de trabajo presencial en el aula con las fases de trabajo autónomo fuera de ella, en una opción metodológica que denominamos autoaprendizaje integrado (Esteve, 2002: 37) y que la tradición anglosajona conoce como blended learning. La pertinencia de este enfoque resulta plenamente vigente en nuestros días habida cuenta de los principios generales que conlleva la implementación del EEES: 
- proceso de enseñanza / aprendizaje basado en competencias,

- papel central del estudiante en este proceso,

- fomento de la autonomía de los aprendices.

Como veremos a continuación, nuestra propuesta de organización de la enseñanza / aprendizaje de la traducción jurídico-económica responde a estos tres principios.

La educación superior vive en nuestro país un momento de renovación de la metodología docente en el que el cambio más radical supone sustituir una larga tradición de enseñanza basada en la transmisión de contenidos por un aprendizaje basado en la acción. Con este objetivo, los programas de las asignaturas se deben presentar no ya como listas de contenidos que deben aprenderse sino en términos de competencias que deben alcanzarse en mayor o menor grado. En este contexto, el objetivo que persiguen los estudios en Traducción e Interpretación no es otro que preparar a los estudiantes a traducir y a interpretar, es decir a actuar. Sin embargo, también es cierto que para los docentes supone un reto importante el diseñar las asignaturas en términos de competencias y subcompetencias en las que se pueden desglosar, considerando la relación que se establece entre dichas competencias y los contenidos, la tipología de actividades, tareas y ejercicios que se proponen para alcanzar los objetivos previstos y a la(s) modalidad(es) de evaluación que se prevén desde el inicio del proceso.

Nuestra propuesta se inscribe plenamente en lo que se ha venido en llamar la "metodología de Bolonia" puesto que, entre otros principios que comentaremos más adelante, toma como punto de partida un enfoque competencial de la enseñanza / aprendizaje de la traducción jurídica. Así, la guía docente de la asignatura "Traducción juridicoeconómica B-A I (francés-castellano-catalán)" en la que situamos nuestra propuesta plantea los siguientes objetivos y competencias:

\section{OBJETIVOS}

La asignatura Traducción especializada juridicoeconómica I (francés-castellano/catalán) tiene como objetivo principal conseguir que los estudiantes empiecen a desarrollar la competencia traductora en el ámbito juridicoeconómico. Asimismo, se espera que los estudiantes se familiaricen con los principales géneros discursivos de dicho ámbito de especialidad y sean capaces de llevar a cabo satisfactoriamente encargos de traducción diversos de escasa dificultad. Para ello, deberán trabajarse las competencias generales y específicas que se detallan a continuación.

\section{COMPETENCIAS}

A. Instrumentales

1) Comprensión textual (francés)

- Capacidad de aplicar estrategias de comprensión a textos juridicoeconómicos de nivel inicial y extensión media. 
Esto implica desarrollar las subcompetencias siguientes:

- Capacidad de comprender conceptos básicos del ámbito temático del derecho y la economía

- Capacidad de identificar y comprender referentes extralingüísticos propios de la cultura de partida, tanto jurídicos como económicos

2) Análisis textual (francés)

- Capacidad de situar los textos en el ordenamiento jurídico y en el ámbito económico de la cultura de partida

- Capacidad de analizar el texto de partida desde el punto de vista microtextual, macrotextual y peritextual

- Capacidad de identificar convenciones propias de la lengua, el estilo o el texto de partida

3) Transferencia textual (francés-castellano/catalán)

- Capacidad de producir un texto jurídico o económico en lengua de llegada que mantenga una relación con el texto de partida suficiente para que se considere una traducción

Esto implica desarrollar las subcompetencias siguientes:

- Capacidad de detectar posibles problemas de traducción y tomar decisiones para resolverlos en función del encargo

- Conocer las distintas posibilidades de traducir un elemento especializado propio de la cultura de partida en función del elemento en cuestión y las características del encargo (técnicas de traducción: equivalente establecido, préstamo, amplificación, adaptación...)

B. Interpersonales

- Capacidad de justificar ante terceros las decisiones adoptadas durante el proceso de traducción de un modo coherente

C. Sistémicas

- Capacidad de planificar y organizar el tiempo de trabajo de manera adecuada

- Capacidad de trabajar individualmente, tanto de forma autónoma como guiada

Una vez expuestos los principios del enfoque competencial que adoptamos, cabe plantearse en qué medida la perspectiva que adoptamos repercute en el papel que deben asumir tanto docentes como aprendices. En efecto, dejar de centrar los procesos de enseñanza / aprendizaje en la magistralidad del profesor conlleva que se debe otorgar al aprendiz el papel central en este proceso; dicho de otro modo, se pretende que el aprendiz deje de desempeñar el papel de mero receptor para convertirse en el protagonista, en el gestor de su aprendizaje. Por consiguiente, la organización docente que aquí proponemos toma como eje central la actividad del estudiante en las diversas modalidades que esta actividad puede adoptar: presencial, dirigida, autónoma, individual, en cooperación, etc. Es obvio que en este enfoque desem- 
peña un papel preponderante el concepto de autonomía, entendido no como la posibilidad de trabajar con independencia del profesor sino como la "capacité de prendre en charge son propre apprentissage" (Holec, 1979: 31-32). Ello implica asumir la responsabilidad del propio aprendizaje, responsabilidad que se traduce en la toma de decisiones de los múltiples aspectos que supone el aprender: determinar objetivos, definir contenidos y progresiones, seleccionar los métodos, técnicas y estrategias de aprendizaje más adecuados, controlar el desarrollo del proceso y, por último, llevar a cabo la evaluación de los resultados.

\section{La unidad didáctica: Definición y descripción de los elementos constitutivos}

Habida cuenta que la terminología es a menudo heterogénea, debemos ante todo definir la unidad mínima de organización del proceso de enseñanza / aprendizaje que proponemos. En el campo de la enseñanza de las lenguas extranjeras se usa con mayor frecuencia el término "tarea", aunque en nuestro ámbito se prefiere el término "encargo de traducción", sobre todo porque es un concepto plenamente consolidado en los Estudios de Traducción. Además, recoge la idea de globalidad que implica el hecho que las diversas actividades que se abordan a lo largo de la unidad tienen un único objetivo comunicativo final: la traducción de un texto. Para realizar el encargo se abordan "actividades" de distinta naturaleza. Así pues, podemos definir la unidad didáctica como una sucesión de tareas o actividades vinculadas a un género textual concreto que para su desarrollo exigen alternar las fases de trabajo presencial en el aula con las fases de trabajo autónomo fuera de ella (Fernández, 2003).

Más concretamente, las unidades didácticas responden a un objetivo comunicativo final: producir un texto meta adecuado con respecto a las instrucciones del encargo de traducción. Presentan una organización cíclica que parte de la globalidad (texto original-TO) y vuelve a la globalidad (texto meta-TM) después de haber abordado, en una etapa intermedia, actividades específicas sobre comprensión y reformulación textuales. Así, el plantear la unidad partiendo del encargo de traducción, implica que todo lo que se haga en las fases siguientes responderá a las necesidades que impone este objetivo, es decir: ¿qué necesita saber el aprendiz para producir un texto meta que cumpla los requerimientos del encargo?

Por consiguiente, lo más importante es que el objetivo comunicativo final es lo que justifica las distintas actividades y estas responden al recorrido traductológico (comprensión-documentación-transferencia) que debería realizarse para cumplir el encargo. Con este objetivo, las actividades que diseñamos incitan al aprendiz a:

a) Ser consciente de los problemas de traducción que plantea el cumplimiento del encargo.

b) Buscar estrategias de resolución de problemas y recursos para superarlas ${ }^{3}$.

\footnotetext{
${ }^{3}$ Estrategias que, en ciertas ocasiones, son aplicables a otros problemas de traducción similares en diferentes encargos.
} 
c) Seleccionar la estrategia más adecuada y concretarla en una técnica de traducción (cuando el aprendiz dispone de varias técnicas de traducción que resuelven el problema ha de ser capaz de identificar la más adecuada con respecto a las instrucciones del encargo).

d) Comprobar su efectividad (el aprendiz debe ser capaz de revisar el resultado con el fin de detectar las ganancias y pérdidas que inevitablemente se producen y establecer posibles compensaciones).

Presentamos de modo sintético, a continuación, la unidad didáctica que desglosaremos en los apartados siguientes.

\section{SECUENCIA DIDÁCTICA ${ }^{4}$ : ITINERARIO ENTRE EL AULA Y EL TRABAJO AUTÓNOMO A PARTIR DEL ENFOQUE POR TAREAS}

Presentación del objetivo comunicativo final de la secuencia didáctica en forma de encargo de traducción:

El portal francés especializado en derecho Virtualegis va a traducirse al castellano y el responsable del mismo te encarga la traducción de este comentario de jurisprudencia sobre la autorización de publicar la imagen de una persona pública. El portal se dirige, principalmente, a especialistas en la materia y los textos traducidos se publicarán en soporte electrónico.

- Trabajo autónomo I

Lectura atenta del texto con la ayuda de ficha de comprensión elaborada por la docente.

- Trabajo en el aula I

1) Aproximación global al TO:

Comentario de las posibles dudas de comprensión que los aprendices no hayan sabido resolver.

Descripción top-down de las características discursivas más relevantes del TO.

2) Planificación de la traducción:

Identificación de posibles problemas de traducción. Primera propuesta intuitiva de posibles vías para la resolución de los problemas (lluvia de ideas: método global de traducción, técnicas concretas, necesidad de documentación, necesidad de textos paralelos, necesidad de consulta a expertos, posibles recursos lexicográficos y electróni$\cos . .$.$) .$

\footnotetext{
${ }^{4}$ Cañada (2004).
} 
- Trabajo autónomo II

Los aprendices, con la ficha pedagógica como guía, producen una traducción adecuada con respecto al encargo que han recibido (toma de decisiones).

- Trabajo en el aula II

Un aprendiz propone su versión, los demás reflexionan sobre la idoneidad de la propuesta y presentan, a su vez, sus versiones personales, que son objeto de comentario y análisis entre el docente y los aprendices (diálogo constructivo). El objetivo último es mejorar la competencia traductora de los aprendices sistematizando soluciones de traducción que puedan ser útiles en otro tipo de encargos. Producción conjunta de una versión consensuada que estará disponible en el aula virtual de la UPF.

Itinerario autónomo de consolidación (optativo)

El docente propone otras actividades optativas y traducciones complementarias del mismo género discursivo para trabajar de forma autónoma en función de las necesidades de cada aprendiz.

\subsection{El texto original y la ficha de comprensión}

Una de las premisas fundamentales en nuestra concepción pedagógica es trabajar siempre con textos auténticos, es decir, aquellos que no han sido elaborados o manipulados para su utilización didáctica, de fuentes diversas, cuya selección obedece, esencialmente, a los criterios siguientes:

a) Se inscriben en un encargo de traducción frecuente o posible en la práctica profesional de la traducción jurídica. Ello se debe a que uno de los objetivos didácticos subyacentes es orientar a los aprendices hacia la práctica profesional desde el primer momento ("socialización del traductor", Monzó, 2003) y permitirles adquirir una metodología de trabajo que les ayude a afrontar con garantías los retos del mundo laboral.

b) Constituyen muestras representativas de un género del discurso jurídico. Por lo tanto, son documentos que plantean problemas de traducción susceptibles de aparecer en otros textos del mismo género. De este modo, los aprendices adquieren conocimientos sobre los distintos géneros jurídicos en lengua original y en lengua meta; además, aprenden a activar estrategias traductoras que les ayuden a resolver esos mismos problemas traductológicos en otros textos.

c) Presentan un nivel de dificultad adecuado para la etapa de la formación en que se encuentran los estudiantes. La dificultad y extensión de los textos debe seguir una gradación ascendente, de manera que se reservan para etapas posteriores los encargos de traducción más complicados, tanto por cuestiones vinculadas con el texto original (estilísticas, genéricas o por falta de correspondencia entre conceptos jurídicos), como con la situación de comunicación 
(aquellos encargos que exigen un mayor grado de manipulación textual para satisfacer las demandas del iniciador).

Una vez escogido el texto original que constituirá el eje de la unidad didáctica (véase anexo I), proponemos a los aprendices una lectura crítica del mismo donde se anticipen a los posibles problemas de traducción con que vayan a enfrentarse. Tras esta lectura crítica, los aprendices realizan los ejercicios propuestos en la ficha de comprensión. En este documento, que los aprendices han de completar antes de traducir, el docente plantea preguntas sobre el contenido del texto original y propone ejercicios sobre el campo temático en el que este se inscribe.

Siguiendo la aproximación al texto que propone Tricás (1995: 69-70), los ejercicios de la ficha de comprensión se organizan con arreglo a los tres niveles de la textualidad (véase anexo II). En primer lugar, en el nivel peritextual se abordan cuestiones relativas al marco cultural jurídico donde se inserta el texto. Seguidamente, en el nivel macrotextual se proponen ejercicios relativos a la unidad textual considerada en su globalidad (mecanismos retóricos y estilísticos, estructura argumentativa y organización interenunciativa). Por último, en el nivel microtextual se tratan cuestiones terminológicas y léxicas, gramaticales y grafémicas.

La finalidad general de la ficha es apuntalar la comprensión del texto y obligar al aprendiz a realizar tareas de documentación previas al proceso traductor, que le facilitarán el trabajo posteriormente (para un ejemplo de este tipo de tareas, véanse los ejercicios 5 y 6 del anexo II, pág. 199). De forma complementaria, la ficha puede ser de utilidad para recordar conceptos o cuestiones ya tratadas en otros textos que sea necesario activar en la traducción de la unidad didáctica y para repasar cuestiones de lengua francesa que planteen alguna dificultad.

La realización de los ejercicios incluidos en la ficha es una tarea obligatoria, que los estudiantes llevan a cabo de forma autónoma. La corrección también puede realizarse de igual modo, mediante un solucionario facilitado por el profesor, o de forma guiada en el aula.

\subsection{La ficha pedagógica}

La ficha pedagógica constituye la columna vertebral de la unidad didáctica, pues funciona como guía que articula el proceso de traducción y las tareas complementarias que el aprendiz deberá realizar. Está dividida en dos apartados claramente diferenciados: uno dedicado a la descripción del encargo de traducción y otro donde se plantean las cuestiones de análisis textual que deberán tenerse en cuenta durante el acto interpretativo del traductor.

El primer apartado, la descripción del encargo de traducción, se inicia con la referencia completa del documento que deberá traducirse, acompañada de una descripción lo más detallada posible del encargo y su iniciador (véase anexo III). El docente, aún sabiendo que se trata de una simulación, debe intentar que resulten plausibles en el mundo laboral donde vayan a actuar los futuros traductores. Así, pues, el encargo debe contener la máxima información sobre el contexto comunica- 
tivo donde vaya a insertarse el nuevo texto, para que el aprendiz esté en disposición de tomar decisiones traductológicas y concretarlas de forma autónoma. Por lo tanto, el objetivo específico de la ficha pedagógica es constituir el marco comunicativo general donde va a inscribirse el encargo.

A continuación, en la segunda sección de la ficha, se presentan diversas cuestiones relativas al análisis textual que el docente considera importantes para la comprensión y el análisis interpretativo del texto. Se trata de cuestiones tanto lingüísticas como de cultura jurídica, que los aprendices deberán traducir con especial atención o tomar en consideración para concretar sus decisiones. Para adoptar un enfoque de análisis textual más sistemático y familiar para el aprendiz, hemos recuperado aquí la triple división en niveles peritextual, macrotextual y microtextual que habíamos utilizado en la ficha de comprensión. Posteriormente, el docente retomará estas cuestiones y las tratará con más detalle durante la fase de corrección presencial.

Una vez establecido el marco general del proceso de traducción, se presentan los objetivos pedagógicos de la unidad didáctica, que variarán en función del nivel académico de los aprendices, del texto y de los aspectos lingüísticos, traductológicos o culturales que el docente desee enfatizar.

\subsection{El material complementario}

En traducción jurídica resulta esencial poseer un buen conocimiento del campo temático en que se inscribe el texto para poder salvar de forma adecuada el escollo que supone la falta de equivalencia entre sistemas legales. Por ello, teniendo en cuenta las características del alumnado de Traducción e Interpretación, que suele presentar carencias de conocimiento temático, resulta útil elaborar fichas que recojan cuestiones o términos jurídicos interesantes para la traducción. Estas fichas permitirán ampliar el conocimiento enciclopédico de los aprendices.

Asimismo, pueden contemplarse otros ejercicios, como la elaboración de glosarios, la búsqueda de textos paralelos en lengua $\mathrm{A}$ y en lengua $\mathrm{B}$ o actividades paralelas de redacción en lengua A y B. El material complementario puede ser elaborado por el docente, por los aprendices de forma autónoma o por ambos, en función de las necesidades del alumnado y de las características del texto.

\section{Aplicación práctica: organización de las actividades}

Una vez descrito el material que constituye la unidad didáctica, proponemos seguidamente un posible itinerario entre el trabajo que los aprendices realizan en el aula y el trabajo autónomo a partir del enfoque por tareas. (2000).

5 Esta posible organización de las actividades de traducción jurídica se inspira en el trabajo de Esteve 
Una vez presentado a los aprendices el objetivo general de la secuencia didáctica (en forma de encargo de traducción) y los distintos objetivos específicos, el trabajo podría organizarse con arreglo a las siguientes etapas:

- Trabajo autónomo previo de preparación I (dedicación: 30-45 min)

1. Lectura atenta del texto y activación de estrategias de comprensión.

2. Los aprendices hacen los ejercicios planteados en una ficha de comprensión elaborada por el profesor, que contempla los niveles peritextual, macrotextual y microtextual del texto original.

- Trabajo en clase I (dedicación: 30-45 min)

1. Aproximación global al texto original:

- Los aprendices plantean al profesor las dudas de comprensión que les puedan haber quedado sin resolver. Comentario de la ficha de comprensión.

- Descripción top-down y comentario en grupo de las características discursivas más relevantes del texto original (con la ficha pedagógica).

2. Planificación de la traducción (interacción en el aula):

- Identificación de posibles problemas de traducción por parte de los aprendices e introducción de otras posibles dificultades por parte del profesor (con la ficha pedagógica). Entre todos, clasificación de los problemas en los ámbitos peritextual, macrotectual y microtextual.

- Primera propuesta intuitiva de posibles vías para resolver los problemas de traducción por parte de los aprendices (lluvia de ideas): estrategia global de traducción, métodos concretos para resolver cada problema o dificultad, necesidad de textos paralelos, necesidad de consulta a expertos, posibles recursos lexicográficos, electrónicos, temáticos...

\section{- Trabajo autónomo II (dedicación: según necesidades del aprendiz)}

Los aprendices, con ayuda de la ficha pedagógica, traducen el texto de forma autónoma en función del encargo de traducción que han recibido. Para apuntalar la comprensión del texto original, acaban de documentarse en función de sus lagunas de conocimiento (análisis de necesidades). Producen una primera versión personal del texto original.

\section{- Trabajo en clase II (dedicación: 1 h 15 min- 1 h 30 min)}

1. Un aprendiz propone su versión y describe cómo ha resuelto los problemas señalados anteriormente (recursos para la traducción especializada). Los demás aprendices reflexionan sobre la idoneidad de la propuesta y presentan, a su vez, sus versiones personales, que son objeto de comentario y análisis entre docente y aprendices. Se elabora entre todos una versión final de la traducción.

2. A partir de las propuestas de los aprendices y de sus explicaciones sobre el recorrido traductológico que han seguido, el docente y los aprendices intentan establecer una metodología en la resolución de problemas. El objetivo 
último es mejorar la competencia traductora de los aprendices sistematizando comportamientos traductores que pueden ser útiles para encargos posteriores.

3. Actividades de consolidación (son opcionales y se realizan en función de la respuesta de los aprendices): el profesor propone otros ejercicios que permitan trabajar de forma autónoma aspectos textuales o traductológicos de especial interés o que hayan planteado más dificultades de las previstas por el docente. Podría tratarse de actividades como:

a) Ejercicios de comprensión (en lenguas $\mathrm{B} / \mathrm{C}$ )

b) Ejercicios de reexpresión (lengua A): traducción de unidades léxicas específicas; traducción de unidades léxicas que aparecen en el texto en otros contextos; traducción de mini-textos con expresiones problemáticas...

c) Traducción complementaria de un texto de temática similar, perteneciente al mismo género discursivo.

\section{Conclusiones}

En estas páginas hemos presentado de forma sintética una propuesta didáctica elaborada desde los principios del constructivismo en la que el trabajo por competencias y el fomento de la autonomía del aprendiz desempeñan un papel preponderante. En efecto, las unidades didácticas presentan siempre un objetivo competencial último (a saber, ser capaz de traducir un texto especializado del ámbito jurídico) que puede desglosarse en competencias de nivel inferior; estas subcompetencias se corresponden con las distintas fases de la secuencia de trabajo (comprensión del $\mathrm{TO}$, conocimiento de la cultura extranjera, reformulación interlingüística, etc.). Una metodología como la que proponemos permite al aprendiz situar su proceso de enseñanza / aprendizaje en un marco cercano a la realidad profesional a la que se incorporará en poco tiempo de tal manera que sólo de él depende el grado de profundidad con el que trabaje la unidad. Así, las unidades didácticas permiten que, desde el inicio, el aprendiz sea consciente de sus logros y sus necesidades, y defina el plan de trabajo que mejor se adapta a sus objetivos. Sin embargo, cabe subrayar que el aprendiz no se encuentra solo en este proceso de autonomización de su aprendizaje sino que, por el contrario, se trata de un proceso gradual que empieza de manera más pautada para dejar paso, a medida que transcurre el proceso, a mayores espacios de libertad.

\section{Referencias bibliográficas}

Borja Albi, A. «La enseñanza de la traducción jurídica» en: Hurtado Albir, A. (ed.), La enseñanza de la traducción. Castelló: Universitat Jaume I 1996, 201-205.

Borja Albi, A. «La traducción jurídica: didáctica y aspectos textuales», en: http://cvc.cervantes.es/obref/aproximaciones/borja.htm [consulta: 20-12-2010]. 
Cañada Pujols, M.D., «Voix passive et fait divers, exemple d'unité didactique», en : Suso López, J. y López Carrillo, R. (coords.) : Le français face aux défis actuels. Histoire, langue et culture. Granada: Universidad de Granada 2004, vol. II, 523533.

Consejo de Europa 2001. Marco común europeo para las lenguas: aprendizaje, enseñanza, evaluación, en: http://cvc.cervantes.es/obref/marco [consulta: 11 de junio de 2007].

Esteve Ruescas, O., «L'enfocament per tasques en l'ensenyament de llengües estrangeres com a pont d'unió entre el treball en autoaprenentatge i l'aprenentatge a l'aula» en: Autoaprenentatge: models d'integració dins i fora de l'aula, Departament de Cultura, Col. Com/Materials didàctics 8, 2002, 37-47

Esteve Ruescas, O. y Cañada Pujols, M.D., «Organització i ús de materials d'autoaprenetatge per a la millora de la competència lingüística d'aprenents adults», Articles 34 (2002), 17-33.

Fernández Sánchez, F., «Secuencias didácticas para un aprendizaje autonomizador de la traducción general (alemán-español)», en Elena, Pilar et al. (eds.): II Simposio de la traducción del/al alemán. Salamanca: Ediciones Universidad de Salamanca 2003, 59-70.

Gémar, J.-C., Traduire ou l'art d'interpréter. Langue, droit et société : éléments de jurilinguistique. Québec: Presses de l’Université du Québec 1995.

González Davies, M. (coord.), Secuencias. Tareas para el aprendizaje interactivo de la traducción especializada. Barcelona: Octaedro-EUB 2003.

González Davies, M., Multiple Voices in the Translation Classroom. Activities, Tasks and Projects. Amsterdam: John Benjamins 2004.

Holec, H., Autonomie et apprentissage des langues étrangères. Conseil de l'Europe: Hatier 1979.

Kiraly, D., A Social Constructivist Approach to Translator Education. Empowerment from Theory to Practice. Manchester: St. Jerome Publishing 2000.

Martín Peris, E., «¿Qué significa trabajar en clase con tareas comunicativas?», Red ELE. Revista electrónica de didáctica / Español lengua extranjera, núm. 0 (2004), en: http://www.educacion.es/redele/revista/martin.shtml

Monzó Nebot, E., «La traducción jurídica a través de los géneros: el transgénero y la socialización del traductor en los procesos de enseñanza/aprendizaje», Discursos. Revista de Tradução 2 (2003), 21-36.

Nord, C., Translating as a Purposeful Activity. Functionalist Approaches Explained. Manchester: St. Jerome 1997.

Nunam, D., Designing Tasks for the Communicative Classroom. Cambridge: Cambridge University Press 1989.

Tricás Preckler, M., Manual de traducción francés-castellano. Barcelona: Gedisa 1995. 
Anexo I: El texto original

\section{UNIDAD DIDÁCTICA COMENTARIO DE JURISPRUDENCIA (DERECHO CIVIL)}

\section{L'autorisation de publier l'image d'une "personne publique"}

Toute personne a, sur l'utilisation qui est faite de son image, un droit absolu qui lui permet de s'opposer à sa publication non autorisée et, de manière générale, à son exploitation sans consentement préalable.

La nécessité d'un consentement exprès avant la publication d'une photographie s'apprécie différemment selon que le sujet photographié est une personne " privée " ou une personne " publique ", à savoir une personne exerçant des fonctions publiques ou apparaissant régulièrement dans les médias.

L'atteinte au droit à l'image, prévue par l'article 9 du Code civil est appréciée en considération de la position prise par la personne photographiée au sujet de la publication des photographies litigieuses et notamment en fonction de l'existence ou de l'absence d'une autorisation de publication ou d'exploitation et en fonction de l'objet de celle-ci.

$1^{\circ}$ ) - Lorsque le sujet photographié a interdit formellement et de manière non équivoque la publication de certaines photographies, considérant qu'elles concernent sa vie privée, les tribunaux décident assez systématiquement, que les reporters-photographes et agences de photographie qui ont utilisé les photographies litigieuses, ainsi que les quotidiens, journaux ou revues qui les ont publiés, engagent leur responsabilité civile et doivent être condamnés au paiement de dommages et intérêts destinés à réparer le préjudice causé par l'atteinte au droit à l'image et à l'intimité de la vie privée des personnes concernées.

La Cour d'Appel de PARIS a statué ainsi le 25 octobre 1982 au sujet des époux JARRE, en considérant que l'article 9 du Code civil, qui consacre le droit au respect de sa vie privée, " permet à toute personne, fut-elle artiste de spectacle, de s'opposer à la diffusion, sans autorisation expresse, de son image, attribut de sa personnalité "en relevant que Monsieur TARANTO, reporter - photographe, n'ignorait pas que les époux JARRE n'avaient pas donné leur accord pour la diffusion de la photographie incriminée".

La Cour d'Appel de PARIS, dans une décision du 16 juin 1992, concernant la famille princière GRIMALDI a pris une position équivalente.

$2^{\circ}$ ) - En l'absence d'interdiction formelle, mais également de consentement exprès, la publication de photographies engage également la responsabilité des reporters photographes et des supports, dès lors qu'il s'agit d'images concernant la vie privée des personnes photographiées.

La Cour de Cassation considère que s'il est possible de représenter une personne publique dans l'exercice de la vie publique sans avoir besoin de son autorisation expresse, celle-ci a, comme toute autre personne, droit au respect de sa vie privée et peut s'opposer à toute diffusion de son image, dès lors que celle-ci reproduit des moments de sa vie privée (Civ. 1, 13 avril 1988, Société de Presse Jour de FRANCE c/ l'Impératrice Farah DIBA et autres).

Les juges du fond se conforment à cette jurisprudence en rappelant régulièrement que faute, pour le reporter - photographe ou le magazine, de justifier d'un consentement exprès et préalable, la publication ou l'exploitation des clichés constitue une faute susceptible d'engager sa responsabilité civile notamment lorsqu'il s'agit de clichés concernant la vie 
privée de la personne photographiée et ce même lorsque les photographies sont prises dans des lieux public (TGI de NANTERRE, 21 février 1996, Anne PARILLAUD c/ Société d'Etude et de Développement de la Presse Périodique, Editrice du magazine ICI PARIS MAGAZINE).

Il a été parfois décidé que l'utilisation de certains clichés réalisés dans le cadre des activités professionnelles d'une actrice, sans consentement exprès de sa part, portait atteinte au droit à l'image dans la mesure où il lui appartenait "de contrôler l'utilisation de son image" (TGI PARIS, 6 mars 1996, Béatrice DALLE c/ Société RCS FRANCE, Editrice de MAX).

S'agissant, en particulier, des mannequins et modèles, la position des Tribunaux en ce sens est plus ferme encore, dans la mesure où l'accord donné par un mannequin professionnel à une utilisation particulière de son image ne peut être considéré comme un accord tacite à une utilisation massive du cliché, le mannequin pouvant s'opposer à une utilisation à titre gratuit ou éventuellement à une dégradation de la valeur marchande de son image.

Sur le fondement des règles qui viennent d'être rappelées, certains hébergeurs de sites web ont été condamnés, pour n'avoir pas pris les précautions nécessaires pour éviter la reproduction, sans autorisation expresse du sujet photographié, d'images dénudées de mannequins (affaires Estelle HALLIDAY c/ V. LACAMBRE et Lydia LACOSTE c/ ESTEREL et France Cybermédia) alors même que les hébergeurs n'ont pas, à priori, au regard du droit communautaire, d'obligation en matière de surveillance des informations ou données qu'ils transmettent ou qu'ils stockent et qu'ils n'ont pas, en fait, la possibilité d'effectuer un tel contrôle sur l'ensemble des sites hébergés qui, rappelons-le, sont modifiés de manière hebdomadaire ou quotidienne.

Pascal ALIX

Avocat au barreau de Paris

Chargé de cours au C.N.A.M. 


\section{Anexo II: Ficha de comprensión del texto original con las soluciones de los ejercicios planteados}

- Referencia del texto original: «L'autorisation de publier l'image d'une personne publique», en www.virtualegis.com

\section{NIVEL PERITEXTUAL}

1.- Sitúa el texto en el contexto jurídico en que se ha producido especificando su temática y en qué rama del derecho se inscribe.

El texto es un comentario de jurisprudencia relativa al tratamiento de la imagen de los famosos por parte de algunos medios de comunicación. Por consiguiente, versa sobre el derecho a la propia imagen y se inscribe en el ámbito del derecho civil.

2.- ¿Quién es el autor del texto y a qué se dedica?

El autor del texto es Pascal Alix, miembro del Colegio de Abogados de París y docente del Conservatoire Nationale des Arts et Métiers (CNAM).

3.- ¿Qué personajes famosos aparecen citados en el texto y por qué se les conoce?

Époux Jarre: Jean-Michel Jarre y Charlotte Rampling

Famille Grimaldi: Familia reinante en Mónaco

Farah Diba: Viuda del Sha de Persia y antigua emperatriz de Irán; habitual de las revistas del corazón.

Anne Parillaud: Actriz francesa

Béatrice Dalle: Actriz francesa

Estelle Halliday: Modelo; famosa porque su demanda sobre violación de la intimidad sentó precedente en la jurisprudencia sobre derecho a la intimidad y a la propia imagen. V. Lacambre: Valentin Lacambre (gerente de AlternB); condenado por la difusión de fotografías de la modelo Hallyday en un sitio anónimo que se alojado en su servidor.

Lydia Lacoste: Modelo

4.- En el texto aparecen citados varios tribunales franceses; cítalos y ordénalos de menor a mayor jerarquía.

Las instancias, por orden de menor a mayor jerarquía, son: le Tribunal de Grande Instance, la Cour d'Appel, la Cour de Cassation. 
5.- Vincula cada una de las afirmaciones siguientes a los tribunales franceses que has citado en la pregunta 3:

a) No vuelve a juzgar el caso, sino que verifica la correcta aplicación de las leyes. (Cour de Cassation)

b) Cuando una de las partes no está satisfecha con una sentencia puede recurrir a este tribunal para que vuelva a examinar el caso. (Cour d'Appel)

c) Tribunal civil que se pronuncia sobre litigios cuyo importe no supera los 7.600 euros y dispone de competencias exclusivas en materia de divorcio, patria potestad, sucesión, filiación... (Tribunal de Grande Instance)

\section{ATENCIÓN}

Si has tenido problemas para contestar las preguntas 3 y 4 , puedes repasar las competencias de los tribunales franceses en: a) la pagina web del Ministerio de Justicia francés http://www.justice.gouv.fr, buscando «ordre judiciaire»; b) la obra Les institutions de la France, de Guten, B., Martin, A y Niogret, M. (París, Nathan, 2000), buscando cada uno de los tribunales.

6.- En el texto se cita el artículo 9 del Código Civil francés. Búscalo y reformúlalo brevemente en lengua A (Si no sabes qué recursos de información emplear, puedes consultar la página del gobierno francés para difusión del derecho y buscar ahí el Código Civil francés: http://www.legifrance.gouv.fr).

Chacun a droit au respect de sa vie privée. Les juges peuvent, sans préjudice de la réparation du dommage subi, prescrire toutes mesures, telles que séquestre, saisie et autres, propres à empêcher ou faire cesser une atteinte à l'intimité de la vie privée : ces mesures peuvent, s'il y a urgence, être ordonnées en référé.

\section{NIVELES MACROTEXTUAL Y MICROTEXTUAL}

1.- ¿Qué marcas tipográficas aparecen en el texto y qué función tienen?

Aparecen mayúsculas para destacar nombres propios (de personas y empresas) al citar sentencias. Aparecen negritas para destacar las partes principales del texto.

2.- El autor establece dos grandes bloques textuales señalados con los números $1^{\circ}$ y $2^{\circ} \cdot$ ¿A qué se debe esta división del texto?

La división del texto obedece a la distinción de dos grandes tipos de decisiones judiciales en materia de protección de la propia imagen, en función de si existe o no consentimiento expreso para la publicación de la imagen por parte del famoso. 
3.- ¿Qué suelen decidir los jueces en el primer caso? ¿Qué decisiones menciona el texto como ejemplo del primer caso?

Los jueces suelen condenar a quienes difunden las imágenes del famoso en actos privados por incurrir en responsabilidad civil. Los ejemplos citado son las decisiones relativas a los casos Jarre y Grimaldi.

4.- ¿Qué suelen decidir los jueces en el segundo caso? ¿Qué decisiones menciona el texto como ejemplo del segundo caso?

Los jueces suelen condenar a quienes difunden las imágenes del famoso en actos públicos y privados por incurrir en responsabilidad civil. Los ejemplos citados son las decisiones relativas a los casos Diba, Parillaud y Dalle.

5.- ¿Cuál es la posición de los tribunales en el caso de las modelos? ¿Por qué?

Una posición más firme, porque consideran que un uso particular de la imagen de una modelo no implica un acuerdo tácito para el uso masivo de la fotografía.

6.- ¿Qué sucede en el ámbito de Internet y qué ejemplo se menciona?

En cuanto a Internet, algunos hospedadores han sido condenados por albergan páginas web donde se difundían imágenes de modelos desnudas. Se mencionan como ejemplo las decisiones relativas a los casos Halliday y Lacoste. 


\section{Anexo III: Ficha pedagógica}

\begin{tabular}{|c|c|}
\hline \multicolumn{2}{|c|}{$\begin{array}{c}\text { Referencia del texto original } \\
\text { Alix, Pascal (2002): «L'autorisation de publier } \\
\text { l'image d'une personne publique», en www.virtualegis.com }\end{array}$} \\
\hline & Descripción del encargo de traducción \\
\hline Iniciador & - Responsable del portal especializado Virtualegis.com \\
\hline Encargo & $\begin{array}{l}\text { - El portal francés especializado en derecho Virtualegis va a } \\
\text { traducirse al castellano y el responsable del mismo te encarga la } \\
\text { traducción de este comentario de jurisprudencia sobre la } \\
\text { autorización de publicar la imagen de una persona pública. El } \\
\text { portal se dirige, principalmente, a especialistas en la materia. Los } \\
\text { textos traducidos se publicarán en soporte electrónico. }\end{array}$ \\
\hline \multicolumn{2}{|c|}{ Análisis textual y traducción: explotación pedagógica } \\
\hline Nivel peritextual & $\begin{array}{l}\text { - Contexto extraverbal y situación comunicativa } \rightarrow \text { determinación } \\
\text { de la función del TO y de una estrategia global de traducción } \\
\text { - Repaso de algunos órganos jurisdiccionales franceses: } \\
\text { descripción, competencias y comparación con el ordenamiento } \\
\text { jurídico español }\end{array}$ \\
\hline Nivel macrotextual & $\begin{array}{l}\text { - Organización de la macroestructura textual } \\
\text { - Funcionalidad de los elementos grafémicos } \\
\text { - El participio presente y el gerundio en francés: identificación y } \\
\text { traducción de sus valores discursivos } \\
\text { - El si francés: identificación y traducción de su valor discursivo }\end{array}$ \\
\hline Nivel microtextual & $\begin{array}{l}\text { - Terminología especializada de derecho civil } \\
\text { - Tratamiento de neologismos de campos temáticos afines }\end{array}$ \\
\hline
\end{tabular}




\section{Objetivos competenciales de la unidad didáctica propuesta}

Una vez llevado a cabo el encargo de traducción, los aprendices deben:

- Producir un texto meta ajustado desde el punto de vista peritextual, macrotextual y microtextual al encargo de traducción jurídica propuesto.

- Conocer el funcionamiento y las competencias de instituciones jurídicas francesas (la Cour d'Appel, la Cour de Cassation, les juges du fond, le Tribunal de Grand Instance) y adoptar una estrategia de traducción coherente con el encargo de traducción.

- Conocer ciertos términos y expresiones propias del ámbito especializado y saber traducirlos en función del contexto: atteinte au droit à l'image, engager leur responsabilité civile, dommages et intérêts, statuer.

- Saber identificar los valores lógicos de ciertas expresiones francesas y traducirlos de forma adecuada (si concesivo; expresiones no personales: participio presente especificativo, participio presente causal; gerundio causal...). 